\title{
Pharmacological Adjuvants to Limit Erythropoietin Stimulating Agents Exposure
}

\author{
Iqbal Masood, Geoffrey Teehan \\ Department of Nephrology, Lankenau Medical Center and Lankenau Institute for Medical Research, \\ Wynnewood, USA \\ Email: iqbalmasood@msn.com,gteehan@comcast.net
}

Received August 23, 2012; revised October 5, 2012; accepted October 20, 2012

\begin{abstract}
Anemia in chronic kidney disease (CKD) is common, causing morbidity and mortality, and is primarily due to reduced erythropoietin (EPO) release and, to a lesser degree, shortened red cell survival. Erythropoietin Stimulating Agents like epoetin Alfa and darbepoetin alpha are used commonly to treat this form of anemia. Recent evidence suggests increased morbidity and mortality associated with higher hemoglobin in the setting of these agents use. Whether these complications are due to higher dose of erythropoietin or its resistance (i.e., inflammation), or achieving a higher hemoglobin remains unclear. Tightening restrictions on these agents has led to increase interest in the use of non-ESA adjuvants to improve erythropoiesis. This review will highlight the most promising of these agents.
\end{abstract}

Keywords: Anemia; Chronic Kidney Disease (CKD); End Stage Renal Disease (ESRD); Erythropoiesis Stimulating Agents (ESA); Epoetin Alfa (EPO)

\section{Introduction}

Anemia in chronic kidney disease (CKD) is common, causing morbidity and mortality, and is primarily due to reduced erythropoietin release and, to a lesser degree, shortened red cell survival $[1,2]$. The National Health and Nutrition Examination Survey (NHANES) and the Prevalence of Anemia in Early Renal Insufficiency (PAERI) studies suggest the incidence of anemia in CKD stage $\mathrm{V}$ is more than $70 \%$ [3]. As renal function declines, anemia prevalence increases in CKD, and its associated morbidities generally worsen [4-8].

Since the approval of recombinant human erythropoietin (epoetin Alfa, EPO) by the United States Federal Drug Administration, this and similar therapeutic agents like darbepoetin alpha (DPO) and recently approved once a month agent, methoxy polyethylene glycol-epoetin beta, called Erythropoiesis Stimulating Agents (ESAs) have become the standard of care for the treatment of the erythropoietin-deficient, normocytic anemia that occurs in most patients with CKD. Due to wide spread use of ESA, average hemoglobin in patients with CKD has increased [9]. Recent evidence suggesting increased morbidity and mortality associated with higher hemoglobin levels in the setting of ESA use has spurred interest in pharmacological adjuvants to limit ESA exposure [10-12]. Whether these complications are due to the higher dose of erythropoietin, ESA resistance (i.e., inflammation), or achieving higher hemoglobin, remains unclear.
Nevertheless, all ESAs now come with a "black box warning" recommending physicians to weigh the benefits of ESA use in anemia of CKD to decrease the need for transfusions against the increased risks for serious adverse cardiovascular events. Further, dosing should be individualized to use the lowest dose of ESA sufficient to reduce the need for transfusion. Although a target hemoglobin range is not provided, the insert states that for patients with CKD who are not on dialysis ESA treatment should only begin when the hemoglobin level is less than $10 \mathrm{~g} / \mathrm{dL}$ and reduce or stop the ESA dose if the hemoglobin level exceeds $10 \mathrm{~g} / \mathrm{dL}$. For patients on dialysis, one should initiate ESA treatment when the hemoglobin level is less than $10 \mathrm{~g} / \mathrm{dL}$ and reduce or interrupt the ESA dose if the hemoglobin level approaches or exceeds $11 \mathrm{~g} / \mathrm{dl}$ [13].

The 2012 Kidney Disease Improving Global Outcome (KDIGO) [14] recommends the same cut off for ESA initiation in patients with CKD (non-dialysis) and End Stage Renal Disease (ESRD) on dialysis. They also recommend not to use ESA to keep hemoglobin $>11.5 \mathrm{mg} /$ dl. Tightening restrictions on these agents has led to the use of non-ESA adjuvants to improve erythropoiesis. This review will highlight the most promising of these agents.

\section{Iron}

Iron is a vital to hematopoiesis. The extracorporeal process of Hemodialysis (HD) promotes constant blood, and 
therefore iron loss with such patients, losing an average of $2 \mathrm{~g}$ of iron yearly, and subsequent iron deficiency. Reduced iron stores or decreased availability of iron are the most common reasons for resistance to ESA agents [15]. Iron, either IV or oral iron replete lost iron aiding erythropoiesis.

\subsection{Diagnosis of Iron Deficiency}

Before starting EPO therapy, iron stores must be assessed and non-renal causes of anemia excluded. The evaluation should include testing for fecal occult blood, red blood cell indices, reticulocyte count, serum iron, total iron binding capacity, percent transferrin saturation, serum Ferritin and content of hemoglobin in reticulocyte (where available) [16,17]. Vitamin deficiencies should be corrected in CKD patients [18]. In CKD and ESRD-associated anemia, a different standard is applied to determine adequate iron stores for erythropoiesis [16].

\subsection{Absolute Iron Deficiency in CKD}

Absolute iron deficiency in CKD occurs when the percent transferrin saturation (TSAT) (plasma iron divided by total iron binding capacityX100) falls below $20 \%$, and the serum Ferritin concentration is under $200 \mathrm{ng} / \mathrm{mL}$ (among Hemodialysis patients) or below $100 \mathrm{ng} / \mathrm{mL}$ among predialsyis and peritoneal dialysis (PD) patients.

\subsection{Functional Iron Deficiency}

Functional iron deficiency occurs when adequate iron stores, as defined by conventional criteria, are present, but the iron cannot be mobilized from hepatic and other storage sites to support erythropoiesis even with ESA use. The TSAT is less than $20 \%$, but with elevated ferritin levels (more than $100-200 \mathrm{ng} / \mathrm{mL}$ ). Usually responsive to iron therapy, functional iron deficiency must be differentiated from inflammatory iron block, which may or may not respond to supplemental iron therapy, and can lead to refractory anemia [17]. Table 1 outlines these iron storage states. The response to ESA and or IV iron may help distinguish between these two.

\subsection{A Response to ESA}

With increasing dose of ESA, ferritin levels may decrease with increase in hemoglobin levels in patients with functional deficiency but not with inflammatory iron block.

\subsection{B Response to Iron}

Inflammatory block is suspected if weekly administration of intravenous iron along with increasing dose of ESA fails to increase hematocrit with progressive increase in ferritin concentration. In contrast, patients with functional
Table 1. Different iron states.

\begin{tabular}{cccc}
\hline Labs & $\begin{array}{c}\text { Absolute iron } \\
\text { deficiency }\end{array}$ & $\begin{array}{c}\text { functional iron } \\
\text { deficiency }\end{array}$ & $\begin{array}{c}\text { Inflammatory } \\
\text { iron block }\end{array}$ \\
\hline Ferritin & $<200$ & $>200$ & $>200$ \\
Hemodialysis & & & \\
Pre-dialysis/PD & $<100$ & $>100$ & $>100$ \\
Percent saturation & $<20$ & $<20$ & $<20$ \\
Response to IV iron & ++++ & ++ & $+/-$ \\
\hline
\end{tabular}

iron deficiency, additional intravenous iron with concomitant increases in ESA can be effective in increasing hemoglobin levels, as shown in Dialysis Patients Response to IV Iron with Elevated Ferritin (DRIVE) study [19], in which anemic subjects with elevated ferritin levels $(500-1200 \mathrm{ng} / \mathrm{mL})$ and low TSAT $<25 \%$, who were on high doses of ESA, were randomly assigned to IV iron or placebo. ESA dose was increased by $25 \%$ in all patients at the beginning of study. At six weeks, hemoglobin levels increased more in the active therapy group. Post hoc analysis of DRIVE study showed that none of the iron parameters used in clinical practice is sensitive to predict response to iron supplementation [20].

Hepcidin, a key regulatory protein, controlling intestinal absorption of iron and its distribution throughout the body, may partially explain these observations regarding iron. Produced by the liver, high-circulating hepcidin reduces iron absorption in response to oral or intravenous iron. Conversely, limited iron leads to low hepcidin levels, which allows enhanced intestinal iron absorption and release of storage iron [21,22]. (Figure 1). Hepcidin, cleared renally, accumulates in renal failure and may contribute to anemia and ESA hypo response. Administration of oral or intravenous iron leads to increase in hepcidin levels, down regulating intestinal iron absorption. Hepcidin levels fall with ESA therapy improving iron mobilization, as well as with hypoxia and anemia. Levels increase with inflammation. Overall, blood hepcidin levels change in a similar manner to ferritin, decreasing with low iron stores, and increasing as iron storage increases, and in inflammatory states, confounding the evaluation of iron status [23].

Not surprisingly then, Hepcidin levels are elevated significantly in patients on dialysis (and less so in CKD stage II-IV), relative to the general population, correlating directly with ferritin levels and inflammatory markers [24-29]. Hepcidin levels inversely correlate with ESA and fall with initiation of ESA use [24,29].

Elevated hepcidin impairs release of stored iron. Parenteral, but not oral iron, can overcome hepcidin-induced iron blockade [29,30] Studies in CKD and dialysis patients show that intravenous iron improves anemia in most patients, including those with elevated hepcidin levels. Iron use however would over express hepcidin 


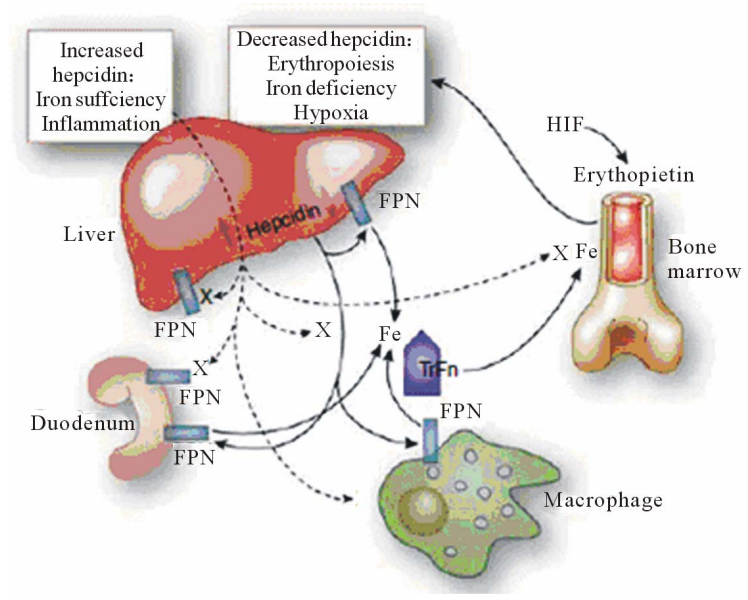

Figure 1. Iron (Fe) sufficiency and inflammation enhance hepcidin production in the liver. Kidney International (2011) 80, 240-244. doi:10. 1038/ki. 2011.141.

further, restricting iron later. Hepcidin and its regulatory pathways are potential therapeutic targets, which could lead to effective treatment of anemia and EPO hypo responsiveness in patients with CKD.

Thus, high hepcidin levels may contribute to the ESA resistance observed in many dialysis patients. Consequently, lowering hepcidin or inhibiting its signaling would release iron from stores, promote erythropoiesis, and prolong red cell survival. This may ultimately be safer than high doses of ESAs with repetitive parenteral iron. Hepcidin and its regulatory pathways are therefore potential therapeutic targets, which could lead to effective treatment of anemia of CKD and ESA hyporesonsiveness.

In animal models, administration of an anti-hepcidin antibody has been shown to treat inflammation-induced anemia when combined with ESA treatment [31].

\subsection{IV versus Oral Iron}

Iron may be given orally or IV to treat and prevent the development of iron deficiency. A trial of oral iron is often recommended for predialsyis patients, but may be limited by gastrointestinal symptoms and limited efficacy. Intravenous iron is preferred in most patients on PD and hemodialysis patients due to poor GI absorption [32-34].

\subsection{Iron in Hemodialysis Patients}

Among hemodialysis patients, oral iron usually is ineffective in raising trasferrin saturation or ferritin. In one study, 39 iron-deficient patients starting hemodialysis but not on ESA were randomly assigned to receive oral iron, intravenous iron or none. Those treated with IV iron had a significant increase in hemoglobin levels [32]. MacDougall et al. studied $37 \mathrm{HD}$ patients beginning ESA therapy with Epogen (EPO) and found the increase in hemoglobin was greater and the EPO dose requirement were lower among those assigned to IV iron, compared to those receiving either oral or no iron. There was no difference in erythropoietic response to ESA in oral or no iron group [33]. Winard et al. prospectively studied 46 patients on EPO, randomized to four different oral iron regimens to give $200 \mathrm{mg}$ of oral iron daily with at least $100 \mathrm{mg}$ of ascorbic acid for 6 months. They found that with compliance, oral iron at the dose used in the study was able to maintain adequate iron status over a short term (less than 6 months) without the need for IV iron Dextran, but eventually IV iron Dextran would be required due to depleted iron stores [34].

Ferumoxytol, an intravenous form of elemental iron, was compared with oral iron by Provenzano et al., and showed a greater increase in mean hemoglobin along with greater increase in TSAT as compared to oral iron, suggesting even in iron-replete patients, those supplemented with IV iron have an enhanced hemoglobin response to EPO with better maintenance of iron stores and lower dosage requirements of EPO [35]. The preferred route of administration of iron in patients with ESRD on HD is intravenous as supported by National Kidney Foundation Disease Outcomes Quality Initiative (NKF KDOQI) of 2006 [36]. Recently published 2012 Kidney Disease Improving Global Outcome (KDIGO) [14] guidelines suggest a trial of IV Iron in patient with ESRD on HD if an increase in hemoglobin is desired without using ESA and if TSAT is $<30 \%$ and ferritin is $<500 \mathrm{ng} / \mathrm{ml}$.

\subsection{Iron in Pre-Dialysis Patients}

National Kidney Foundation Disease Outcomes Quality Initiative (NKF-KDOQI) guidelines recommend either oral or IV iron for patients with non-ESRD CKD, due to inconsistent data. KDIGO 2012 also recommends a trial of oral iron for $1-3$ months with the same TSAT of $<30 \%$ and ferritin of $<500$ as in ESRD on HD. They also recommended selecting the route of administration based on severity of iron deficiency, response and side effects to prior therapy, patient's compliance and availability of venous access [14].

Contrary to ESRD data, in CKD non-dialysis, multiple trials have failed to show that IV iron is superior to oral iron in hemoglobin response or reduction in EPO dose. In a prospective, controlled trial of 45 anemic patients with non-ESRD CKD, randomized to receive either oral ferrous sulfate (200 mg TID) or intravenous iron Sucrose (300 mg monthly) along with EPO, after an average follow up of 5.2 months, there was no difference in hemoglobin response or EPO dose between the two groups [37]. Another prospective, randomized, controlled trial of 96 non-ESRD CKD patients on EPO, assigned to either IV iron (5 doses of $200 \mathrm{mg}$ Iron Sucrose weekly) or oral iron (ferrous sulfate $325 \mathrm{mg}$ TID), showed that the hemo- 
globin increased in both groups, but only in the IV iron group did the ferritin increase [38]. In a trial of 75 nonESRD CKD patients who were ESA naive were randomly assigned to receive either IV Ferric gluconate $250 \mathrm{mg}$ weekly for 4 weeks or oral ferrous sulfate $325 \mathrm{mg}$ TID for 42 days. Hemoglobin increased in both groups [39].

In another trial of 182 patients with CKD stage III - V, hemoglobin increase of $1 \mathrm{gm}$ or more was more common in the IV treatment group (Sucrose $1 \mathrm{gm}$ in divided doses over 14 days) than in oral iron treatment (ferrous gluconate $325 \mathrm{mg}$ TID for 56 days) [40]. In a phase II trial of Ferumoxytol, 304 patients with CKD were assigned in a 3:1 ratio to two 510-mg doses of intravenous Ferumoxytol or $200 \mathrm{mg}$ of elemental iron orally for 21 days. Among patients who were not on ESA, hemoglobin increased significantly with IV ferumoxytol [41]. Thus in nonESRD CKD, the data are conflicting with regards to the efficacy of IV versus oral iron.

\section{Ascorbic Acid}

Vitamin $\mathrm{C}$ or Ascorbic acid, increases iron release from the reticuloendthelial system, enhancing iron utilization during heme synthesis [42-44]. These findings led to an increased interest in investigating its use in hemodialysis patients with EPO hyporesonsiveness, elevated serum ferritin, and functional iron deficiency. Ascorbic acid levels have been variably reported to be low, normal, or even above normal in dialysis patients. In an observational study Deicher et al. failed to show a significant correlation between Vitamin C plasma levels and response to EPO. They concluded that in some hemodialysis patients Vitamin C levels account, at least partially for the response to EPO, particularly those with EPO-hypo responsiveness and functional iron deficiency [45]. Intravenous Vitamin $\mathrm{C}$ can overcome ESA resistance and "functional iron deficiency" in HD patients and by limiting iron use, may avoid hemosiderosis [46].

A Meta analysis of randomized controlled trials found that Vitamin $\mathrm{C}$ therapy significantly increased hemoglobin levels, decreased EPO dose, and improved trasferrin saturation among hemodialysis patients [47]. These findings were however based on small study sizes with substantial study heterogeneity limiting any solid conclusions about Vitamin C [48-53].

One randomized trial examined patients with EPOhypo responsiveness and or functional iron deficiency [54]. Among 42 patients the EPO dose exceeded $450 \mathrm{IU} /$ $\mathrm{kg}$ per week, the ferritin level was $>500 \mathrm{ng} / \mathrm{ml}$, TSAT $<50 \%$ and the hemoglobin $<11.0 \mathrm{~g} / \mathrm{dl}$. Subjects were assigned to intravenous Vitamin C (300 mg with dialysis) and standard therapy. After six months, active therapy resulted in significantly higher hemoglobin levels (9.3 -
$10.5 \mathrm{~g} / \mathrm{dl}$ vs $9.3-9.6 \mathrm{~g} / \mathrm{dl}$ in standard group), TSAT level (29\% - 37\% vs 29\%) and lower EPO dose in active group (477 to 429 units $/ \mathrm{kg}$ per week vs 474 to 447 units $/ \mathrm{kg}$ per week). No significant adverse effects were reported.

Benz et al. showed that once daily ascorbic acid (500 $\mathrm{mg}$ ) in 21 EPO resistant anemic HD patients significantly decreased ferritin levels and EPO dose requirements while significantly raising hemoglobin and hematocrit. Hemoglobin increased 9\% from $11.4 \%$ to $12.2 \% \mathrm{gm} / \mathrm{dl}$ $(\mathrm{p}=0.05)$, hematocrit increased $10 \%$ from $33.3 \%$ to $36.7 \%(\mathrm{p}=0.05)$, and EPO dose requirement decreased $33 \%$ from 26,229 to $17,559 \mathrm{U} /$ week $(\mathrm{p}=0.03)$. Ferritin levels decreased $21 \%$ from 873 to $691 \mathrm{ng} / \mathrm{mL}(\mathrm{p}=0.004)$. Patients with oxalate levels $>27 \mathrm{micromol} / \mathrm{L}$ were instructed to stop ascorbic acid treatment, and mean levels decreased from 107 to $19 \mathrm{micromol} / \mathrm{L}(\mathrm{p}=0.01)$ over a mean time of 71 days [48].

Secondary oxalosis in hemodialysis patients who received IV Vitamin $\mathrm{C}$ remains a concern $[55,56]$. Oxalate levels have been shown to increase modestly after eight weeks of IV Vitamin C [47]. In one study a progressive increase in plasma oxalate levels occurred when $504 \mathrm{mg}$ Vitamin $\mathrm{C}$ was given into the arterial line throughout each hemodialysis treatment for 12 weeks [57]. In another study, plasma oxalate levels progressively increased as the dose of Vitamin C was increased from 250 to 500 $\mathrm{mg} /$ week. After 6 months, 40 percent of patients attained plasma oxalate levels that exceeded the range that would be associated with calcium oxalate super saturation at usual calcium concentration [58]. Elevated plasma oxalate levels also occur in hemodialysis patients treated with oral Vitamin C [48].

The 2006 KDOQI anemia guidelines in CKD conclude insufficient evidence exists to recommend Vitamin $\mathrm{C}$ as an adjuvant to Epoetin therapy [35]. The European Best Practice Guidelines suggested that correction of impaired Vitamin C status can reduce hypo responsiveness to EPO or functional iron deficiency, but do not recommend routine use [59]. The guidelines noted that use of high dose Vitamin $\mathrm{C}$ requires monitoring but also commented that the risk of oxalate deposition precludes a recommendation for routine use. Also the $2012 \mathrm{KDIGO}$ guidelines recommend not using VITAMIN C, due to lack of sufficient and long term data to address the safety [14].

Further well controlled trials are needed to determine the role of Vitamin $\mathrm{C}$ in anemia of CKD. A short trial of oral or IV Vitamin $\mathrm{C}$ may be tried in selected patients with marked EPO hypo responsiveness who are closely monitored for toxicity and efficacy, and should be reserved for the patients who are unable to achieve and maintain target hemoglobin levels despite adequate iron stores and on high epoetin therapy $(>450 \mathrm{IU} / \mathrm{kg}$ per week). The duration of therapy should not be more than 2 to 6 months. 


\section{Carnitine}

Carnitine is required for the transport of long chain fatty acids into mitochondria. Carnitine also converts acyl CoA which accumulates in renal failure and is toxic, into less toxic acyl Carnitine [60]. Carnitine metabolism is reduced as the glomerular filtration rate falls. Its loss through dialysis has been suggested to result in a Carnitine deficient state. L-Carnitine has been used with or without concomitant ESA [61].

Carnitine increases formation of colony forming unitserythroid (CFU-E) colonies in cell cultures of mouse bone marrow [62]. It has also been suggested to increase red cell survival by reducing red cell osmotic fragility. However there is no convincing evidence yet about the importance of this in ESRD.

Small case series suggest intravenous or oral L-Carnitine may increase hemoglobin levels or reduce the EPO requirement in patients with renal failure and on dialysis [61-63].

A 2002 metaanalysis of six randomized trials evaluated the efficacy of IV Carnitine supplementation in lowering the required dose of EPO. The EPO dose was found to be significantly lower among those administered Carnitine, with a beneficial response reported in four of the six studies [63].

Only a few randomized, controlled trials of L-Carnitine exist in patients with CKD. One such trial in hemodialysis patients, found that treatment with intravenous L-Carnitine was associated with a 37\% reduction in EPO dose without any effect on hematocrit. Neither hematocrit nor EPO dose changed in the control group. A fall in EPO dose was observed in seven of 13 treated patients with maximal benefit by four months [64].

In an open label randomized trial, 55 adult chronic HD patients at a single hemodialysis center were divided into two groups; a group of 20 patients who received 1500 $\mathrm{mg}$ /day oral L-Carnitine and a control group of 35 patients. The mean weekly maintenance dose of erythropoietin was not statistically significantly different in L-Carnitine group $(80.16 \pm 35.61$ units $/ \mathrm{kg})$ and the control group $(91.9 \pm 38.21$ units $/ \mathrm{kg}, \mathrm{p}=0.20)$ [65]. In another randomized control trial involving 14 patients, L Carnitine was not associated with a reduction in EPO dose or change in hematocrit over a six month treatment period [66]. In the post-hoc analysis, there was a nonsignificant trend towards lower EPO dose in patients over the age of 65 .

In another study, patients on Hemodialysis received either 5 or $15 \mathrm{mg} / \mathrm{kg}$ of L Carnitine at each dialysis treatment for 8 months, with IV iron for the first four months with the control group receiving only IV iron. EPO dose did not change over a 4 months period [67]. Mean weekly EPO dose fell by $37 \%$ percent among those receiving L-Carnitine.
In two additional randomized trials in which anemia or EPO dose was not the primary endpoint, there was no change in hemoglobin or epogen dose from baseline in patients on L-Carnitine $[68,69]$.

Intravenous L-Carnitine has been well tolerated apart from a small percentage of patients with seizures and has been recommended by some to be used in selected patients with renal failure and EPO resistance, while some have suggested routine use [61]. Treatment with oral Carnitine up to 3 years has been well tolerated [61] with some concern about the accumulation of toxic metabolites of oral L Carnitine in patients with CKD [70,71].

2006 KDOQI guidelines for anemia of CKD concluded that insufficient evidence exists to recommend LCarnitine [72]. The 2012 KDIGI guideline suggest not using L-Carnitine [14].

\section{Pentoxifylline}

Pentoxifylline is a methyl xanthine derivative with possible anti inflammatory properties [73,74]. Approved for the treatment of peripheral vascular disease, Pentoxifylline has been shown to suppress IL-2, interferon (INF) gamma, TH1 and TH2-derived cytokines [73].

These findings led to the possible application in EPOresistant anemia. The benefits of Pentoxifylline were observed in a small study comprised of 16 patients on HD, PD and failing transplants [75]. The mean hemoglobin increased from 9.5 to $11.7 \mathrm{~g} / \mathrm{dL}$. Epo dose was reduced in only one patient while remaining the same in the rest. One patient, previously transfusion-dependent, was able to stop transfusion. In another study 7 anemic patients with CKD were treated with Pentoxifylline $400 \mathrm{mg}$ daily for 6 months with the goal of defining the effects of Petoxifylline as an agent with anti-tumor necrosis factor (TNF) alpha properties. Petoxifylline-treated patients at 6 months had significant improvement in hemoglobin with reduction of TNF-alpha concentration [76]. Thus Pentoxifylline by virtue of counteracting anti-erythropoietic cytokines may allow epogen dose reducetions in the anemia of CKD. This should be followed up with a larger prospective study to confirm these findings before consideration for common practice. The 2012 KDIGO guideline suggests not using Pentoxifylline at this time due to lack of high-quality evidence [14].

\section{Statins}

Statins are a class of drug use to lower cholesterol by inhibiting HMG-CoA redcutase, which plays a central role in the production of cholesterol in the liver. Statins have some anti-inflammatory and antioxidant properties. In a retrospective study, Sirken et al showed mean hemoglobin rose from 10.6 to $12.5 \mathrm{~g} / \mathrm{dl}$ in 70 hemodialysis patients, with associated $25 \%$ reduction in EPO dose, 
over a mean of 4.7 months after treatment with statin was started [77]. Roughly half of the patients were started on a statin within one month of starting Hemodialysis, limiting generalizabilty. Another study assessed the efficacy of Statins in patients with type 2 diabetes who were on Hemodialysis. The mean EPO dose was significantly lower in statin group [78]. Another prospective study assessed the effects of statin therapy on EPO hypo responsiveness by assessing the anti-inflammatory effects. 30 patients with baseline cholesterol $>220 \mathrm{mg} / \mathrm{dl}$ were prescribed $10 \mathrm{mg}$ of Atorvastatin for 12 weeks. EPO hypo responsiveness defined by EPO to hematocrit ratio was significantly reduced along with reductions in Interleukin 6 and TNF-alpha level suggesting that statin therapy may benefit patients with EPO hyporesonsiveness [79]. Further investigation of the effects of Statins as an Epo adjuvant is needed. For now Statins cannot be recommended at this time to be used solely for the treatment of anemia, but remain a central weapon in combating cardiovascular disease, the most common cause of death in patients with CKD [80].

\section{Androgens}

Before the availability of Epogen, androgens were used routinely to treat anemia in patients with dialysis [81-84]. Androgens may increase endogenous erythropoietin production, sensitivity of erythroid progenitors to the effects of erythropoietin and red blood cell survival. Their role as monotherpay for anemia in CKD patients has declined markedly since epoetin alpha was approved. A possible role of androgens in combination with epoetin therapy in dialysis patient has been evaluated in few small studies with EPO with conflicting results.

One study evaluated 15 patients with ESRD, 8 of whom received intramuscular nandrolone decanoate 1000 mg once weekly in combination with EPO with each dialysis session (the remaining 7 received no androgens). The combination was associated with a greater increase in hematocrit values from 24 to 33 percent as well as greater overall response rate defined as having an increase in hematocrit of $1 \%$ during a two week period. The authors concluded that androgen therapy significantly augments exogenous Epo, resulting in a lower dose of intravenous EPO [85].

A second trial enrolled 12 hemodialysis patients, randomly assigned to receive EPO 40 units/kg IV three times weekly with or without nandrolone decanoate $(2 \mathrm{mg} / \mathrm{kg}$ IM weekly) for 16 weeks. The rate of rise of hematocrit did not differ, and only one of six patients receiving nandrolone reached the HCT target of 30 percent as compared to 3 in the Epo-only group [86].

In another longer open label trial, with low dose EPO therapy [87] 19 chronic HD patients were randomly assigned to receive EPO 1500 units with each HD treat- ment either alone or in combination with nandrolone decanoate $100 \mathrm{mg}$ intramuscularly each week for 26 weeks. With no serious side effects reported, nandrolone group achieved higher final hematocrit values than Epo-alone group $(33.2 \%$ vs $28.3 \%)$ with higher mean increase in hematocrit (8.2\% vs $3.5 \%)$.

Another study of 32 hemodialysis patients randomly assigned to receive low dose EPO therapy 1000 units subcutaneously at each HD treatment either alone or in combination with nandrolone decanoate $50 \mathrm{mg}$ intramuscularly twice weekly for six months showed no statistically significant rise in HCT in nandrolone group compared with the control group with significant side effects of gynecomastia, hirsutism, menstrual irregularities and increase in liver enzymes and triglycerides [88].

The data on androgens are conflicting; prompting both the NKF-K/DOQI and European Best Practice Guideline to conclude their role is limited and further complicated by unwanted side effects $[35,59]$. Cost itself also limits the role of androgens. The $2006 \mathrm{KDOQI}$ guidelines for anemia in CKD stated that androgens should not be used as an adjuvant to epoetin alfa [35]. The 2012 KDIGO guidelines recommend not using androgens.

\section{N-Acetylecysteine}

$\mathrm{N}$-Acetylecysteine (NAC) is used primarily as a mucolytic, for acetaminophen overdoses, and to prevent contrast induced nephropathy $[89,90]$. Due to lack of benefit in preventing contrast induced nephropathy in a recent trial [91], NAC is falling out of favor, but still recommended by KDIGO 2012 to prevent contrast induced nephropathy in high risk patient [92].

There is growing interest in exploring NAC as an adjuvant to EPO due to its antioxidant properties in patients with CKD. In one study, 49 patients on HD received NAC 200mg three times daily for the first 3 months of dialysis, and were compared to 276 patients who did not receive NAC. During the 4-month study, when the EPO dose was stable, only NAC group had significant increase in hematocrit, accompanied with decrease levels of 8-isoprostane and oxidized low-density lipoprotein, both markers of oxidative stress [93].

To determine the contribution of injectable iron administered to HD patients in causing oxidative stress and the beneficial effects of NAC in reducing it, a prospective double blind, cross over trial was conducted on 14 adult hemodialysis patients [94]. To assess for oxidative stress, lipid peroxidation marker, melondiaaldehyde was measured along with highly sensitive C-reactive protein. Non-invasive assessment of endothelial dysfunction was assessed by digital plethysmography before and after intravenous therapy. NAC was found to reduce oxidative stress along with endothelial dysfunction. Thus by reducing the oxidative stress, NAC may reduce EPO hypo- 
Table 2. Summary of different ESA adjuvants.

\begin{tabular}{|c|c|c|c|}
\hline Agent & Strength of evidence & $\begin{array}{l}\text { Recommended by KDOQI or } \\
\text { European best practice guideline }\end{array}$ & Additional comments \\
\hline Oral iron & $\begin{array}{l}\text { Strong for pre-dialysis CKD, not strong } \\
\text { for ESRD on HD. }\end{array}$ & $\begin{array}{l}\text { Recommended for initial trial in } \\
\text { pre-dialysis CKD/PD. }\end{array}$ & Limited by GI side effects. \\
\hline IV iron & Strong: pre-dialysis and ESRD & $\begin{array}{l}\text { Recommended for ESRD on } \\
\text { dialysis and also for pre-dialysis } \\
\text { CKD patients. }\end{array}$ & $\begin{array}{l}\text { IV iron may be able to bypass } \\
\text { hepcidin effect. }\end{array}$ \\
\hline Ascorbic acid & $\begin{array}{l}\text { Mixed. Few small RCTS suggest } \\
\text { some benefit. }\end{array}$ & $\begin{array}{l}\text { NKF-KDOQI does not recommend } \\
\text { use, European best practice } \\
\text { guideline acknowledges benefit but } \\
\text { does not recommends it use. } \\
\text { KDIGO suggest not using. }\end{array}$ & $\begin{array}{l}\text { Secondary oxalosis may occur. } \\
\text { Larger trials needed to confirm } \\
\text { benefit. Consider for short course } \\
\text { in selected patients with severe } \\
\text { EPO resistance. }\end{array}$ \\
\hline Carnitine & $\begin{array}{l}\text { Mixed, small prospective studies suggest } \\
\text { some benefit, while other do not. }\end{array}$ & $\begin{array}{l}\text { NKF-KDOQI: insufficient } \\
\text { evidence to suggest its use. } \\
\text { KDIGO 2012-Do not suggest. }\end{array}$ & $\begin{array}{l}\text { Expensive, seizure has been } \\
\text { reported. }\end{array}$ \\
\hline Androgen & Mixed results. & $\begin{array}{l}\text { NKF-KDOQI does not suggest use. } \\
2012 \text { KDIGO-does not recommend. }\end{array}$ & $\begin{array}{l}\text { Former agent of choice before } \\
\text { ESA as monotherpay. Serious } \\
\text { adverse effects including } \\
\text { abnormal LFTS, risk of } \\
\text { hepatocelullar carcinoma etc. }\end{array}$ \\
\hline Statin & $\begin{array}{l}\text { Small retrospective and prospective study } \\
\text { suggest some benefit. }\end{array}$ & $\begin{array}{l}\text { Not recommended to be used solely } \\
\text { for EPO hypo responsiveness. }\end{array}$ & $\begin{array}{c}\text { Many CKD/ESRD patient already } \\
\text { on statin to reduce CV morbidity } \\
\text { and mortality. }\end{array}$ \\
\hline N-Acetyl cysteine & $\begin{array}{l}\text { Small prospective studies suggest } \\
\text { some benefit. }\end{array}$ & Not recommended at this time. & $\begin{array}{l}\text { Larger trials needed to assess } \\
\text { benefit. }\end{array}$ \\
\hline Pentoxifylline & $\begin{array}{l}\text { Small retrospective studies suggest } \\
\text { some benefit. }\end{array}$ & Not recommended at this time. & $\begin{array}{l}\text { Larger trials needed to assess } \\
\text { benefit. }\end{array}$ \\
\hline
\end{tabular}

responsiveness.

Another small, uncontrolled pilot study enrolled 12 hemodialysis patients treated with $600 \mathrm{mg}$ po BID of NAC showed a $53 \%$ reduction in EPO resistance index (weekly EPO dose per $\mathrm{Kg} / \mathrm{Hematocrit)} \mathrm{[95].}$

These small studies suggest a role for NAC in treating anemia in CKD population, but need larger controlled trial with less confounding factors. Until then, routine use of NAC as an EPO adjuvant cannot be suggested.

\section{Summary (Table 2)}

The high cost of ESAs and the rising incidence of mor bidity and mortality associated with its use have prompted a search for adjuvants to ESAs to limit cost and potential toxicities in CKD and ESRD-associated anemia. Adequate iron stores are essential for effective erythropoiesis and should be corrected. Use of parenteral, as opposed to oral, iron, particularly in ESRD, can overcome some EPO resistance. Identifying correctable causes of anemia (B12/Folate deficiency, gastrointestinal bleeding) and nonrenal causes of anemia (malignancy, hematologic disorders, infections, inflammation) remains vital, as escalating doses of EPO can lead to morbidity and mortality.

Thus far, no one particular adjuvant has proven to be reliably efficacious in improving anemia, reducing ESA dosages, or reducing ESA hyporesonsiveness. IV iron and ESA remain the backbone of all anemia therapy in ESRD. Nevertheless, this review will serve to generate new hypotheses, and may lead to new innovations in anemia management. We believe that Ascorbic Acid, $\mathrm{N}$-Acetyl Cysteine, and targeting hepcidin represent the most promising ways to combat the erythropoietin hypo response, but due to lack of sufficient high quality evidence, should not be routinely use.

\section{REFERENCES}

[1] F. Valderrababano, "Erythropoietin in Chronic Renal Failure,” Kidney International, Vol. 50, No. 4, 1996, pp. 13731391. doi:10.1038/ki.1996.452

[2] J. W. Eschbach, "Erythropoietin 1991-An Overview," American Journal of Kidney Diseases, Vol. 18, Suppl. 4, 1991, pp. 3-9.

[3] B. C. Astor, P. Muntner, A. Levin, J. A. Eustace and J. Coresh, "Association of Kidney Function with Anemia: The Third National Health and Nutrition Examination Survey (1988-1994)," Archives of Internal Medicine, 2002, Vol. 162, No. 12, pp. 1401-1408. doi:10.1001/archinte.162.12.1401

[4] A. Levin, C. R. Thompson, J. Ethier, E. J. Carlisle, S. Tobe, D. Mendelssohn, E. Burgess, K. Jindal, B. Barrett, 
J. Singer and O. Djurdjev, "Left Ventricular Mass Index Increase in Early Renal Disease: Impact of Decline in Hemoglobin," American Journal of Kidney Diseases, Vol. 34, No. 1, 1999, pp. 125-134. doi:10.1016/S0272-6386(99)70118-6

[5] C. T. Jurkovitz, J. L. Abramson, L. V. Vaccarino, W. S. Weintraub and W. M. McClellan, "Association of High Serum Creatinine and Anemia Increases the Risk of Coronary Events: Results from the Prospective CommunityBased Atherosclerosis Risk in Communities (ARIC) Study," Journal of the American Society of Nephrology, Vol. 14, No. 11, 2003, pp. 2919-2925. doi:10.1097/01.ASN.0000092138.65211.71

[6] J. L. Abramson, C. T. Jurkovitz, V. Vaccarino, W. S. Weintraub and W. McClellan, "Chronic Kidney Disease, Anemia, and Incident Stroke in a Middle-Aged, Community-Based Population: The ARIC Study," Kidney International, Vol. 64, No. 2, 2003, pp. 610-615. doi:10.1046/j.1523-1755.2003.00109.x

[7] M. J. Sarnak, H. Tighiouart, G. Manjunath, B. MacLeod, J. Griffith, D. Salem and A. S. Levey, "Anemia as a Risk Factor for Cardiovascular Disease in the Atherosclerosis Risk in Communities (ARIC) Study," Journal of the American College of Cardiology, Vol. 40, No. 1, 2002, pp. 2733. doi:10.1016/S0735-1097(02)01938-1

[8] W. M. McClellan, W. D. Flanders, R. D. Langston, C. Jurkovitz and R. Presley, "Anemia and Renal Insufficiency Are Independent Risk Factors for Death among Patients with Congestive Heart Failure Admitted to Community Hospitals: A Population-Based Study," Journal of the American Society of Nephrology, Vol. 13, No. 7, 2002, pp. 1928-1936. doi:10.1097/01.ASN.0000018409.45834.FA

[9] G. T. Obrador, T. Roberts, W. L. St Peter, E. Frazier, B. J. Pereira and A. Collins, "Trends in Anemia at Initiation of Dialysis in the United States," Kidney International, Vol. 60, No. 5, 2001, pp. 1875-1884. doi:10.1046/j.1523-1755.2001.00002.x

[10] M. A. Pfeffer, E. A. Burdmann, C. Y. Chen, M. E. Cooper, D. de Zeeuw, K. U. Eckardt, J. M. Feyzi, P. Ivanovich, R. Kewalramani, A. S. Levey, E. F. Lewis, J. B. McGill, J. J. McMurray, P. Parfrey, H. H. Parving, G. Remuzzi, A. K. Singh, S. D. Solomon and R. Toto, "TREAT Investigators a Trial of Darbepoetin Alfa in Type 2 Diabetes and Chronic Kidney Disease," New England Journal of Medicine, Vol. 361, No. 21, 2009, pp. 2019-2032. doi:10.1056/NEJMoa0907845

[11] T. B. Drüeke, F. Locatelli, N. Clyne, K. U. Eckardt, I. C. Macdougall, D. Tsakiris, H. U. Burger and A. Scherhag, "CREATE Investigators Normalization of Hemoglobin Level in Patients with Chronic Kidney Disease and Anemia," New England Journal of Medicine, Vol. 355, No. 20, 2006, pp. 2071-2084. doi:10.1056/NEJMoa062276

[12] A. K. Singh, L. Szczech, K. L. Tang, H. Barnhart, S. Sapp, M. Wolfson and D. Reddan, "CHOIR Investigators Correction of Anemia with Epoetin Alfa in Chronic Kidney Disease," New England Journal of Medicine, Vol. 355, No. 20, 2006, pp. 2085-2098. doi:10.1056/NEJMoa065485
[13] http://www.fda.gov/Drugs/DrugSafety/ucm259639.htm

[14] "KDIGO Clinical Practice Guideline for Anemia in Chronic Kidney Disease," Kidney International Supplements, Vol. 2, Vol. 4, 2012, pp. 279-335.

[15] J. W. Eschbach, J. D. Cook, B. H. Scribner and C. A. Finch, "Iron Balance in Hemodialysis Patients," Annals of Internal Medicine, Vol. 87, No. 6, 1977, pp. 710-713.

[16] A. M. Fernández-Rodríguez, M. C. Guindeo-Casasús, T. Molero-Labarta, C. Domínguez-Cabrera, L. Hortal-Casc, P. Pérez-Borges, N. Vega-Díaz, P. Saavedra-Santana and L. Palop-Cubillo, "Diagnosis of Iron Deficiency in Chronic Renal Failure," American Journal of Kidney Diseases, Vol. 34, No. 3, 1999, pp. 508-513.

[17] M. Rambod, C. P. Kovesdy, K. Kalantar-Zadeh, "Combined High Serum Ferritin and Low Iron Saturation in Hemodialysis Patients: The Role of Inflammation," Clinical Journal of the American Society of Nephrology, Vol. 3, No. 6, 2008, pp. 1691-1701. doi:10.2215/CJN.01070308

[18] F. N. Hutchinson and W. J. Jones, "A Cost-Effectiveness Analysis of Anemia Screening before Erythropoietin in Patients with End Stage Renal Disease," American Journal of Kidney Diseases, Vol. 29, No. 5, 1997, pp. 651-657. doi:10.1016/S0272-6386(97)90116-5

[19] D. W. Coyne, T. Kapoian, W. Suki, et al., "Ferric Gluconate Is Highly Efficacious in Anemic Hemodialysis Patients with High Serum Ferritin and Low Transferrin Saturation: Results of the Dialysis Patients' Response to IV Iron with Elevated Ferritin (DRIVE) Study," Journal of the American Society of Nephrology, Vol. 18, No. 3, 2007, pp. 975-984. doi:10.1681/ASN.2006091034

[20] A. K. Singh, D. W. Coyne, W. Shapiro, A. R. Rizkala and DRIVE Study Group, "Predictors of the Response to Treatment in Anemic Hemodialysis Patients with High Serum Ferritin and Low Transferrin Saturation," Kidney International, Vol. 71, No. 11, 2007, pp. 1163-1171.

[21] G. Nicolas, M. Bennoun, I. Devaux, et al., "Lack of Hepcidin Gene Expression and Severe Tissue Iron Overload in Upstream Stimulatory Factor 2 (USF2) Knockout Mice," Proceedings of the National Academy of Sciences of the United States of America, Vol. 98, No. 15, 2001, pp. 87808785. doi:10.1073/pnas. 151179498

[22] E. Nemeth and T. Ganz, "Regulation of Iron Metabolism by Hepcidin," Annual Review of Nutrition, Vol. 26, No. 1, 2006, pp. 323-342. doi:10.1146/annurev.nutr.26.061505.111303

[23] D. Coyne, "Iron Indices: What Do They Really Mean?" Kidney International, Vol. 69, 2006, pp. S4-S8. doi:10.1038/sj.ki.5000404

[24] N. Tomosugi, H. Kawabata, R. Wakatabe, et al., "Detection of Serum Hepcidin in Renal Failure and Inflammation by Using ProteinChip System," Blood, Vol. 108, No. 4, 2006, pp. 1381-1387. doi:10.1182/blood-2005-10-4043

[25] D. R. Ashby, D. P. Gale, M. Busbridge, et al., "Plasma Hepcidin Levels Are Elevated but Responsive to Erythropoietin Therapy in Renal Disease," Kidney International, Vol. 75, No. 9, 2009, pp. 976-981. doi:10.1038/ki.2009.21

[26] J. Zaritsky, B. Young, H. J. Wang, et al., "Hepcidin-A 
Potential Novel Biomarker for Iron Status in Chronic Kidney Disease," Clinical Journal of the American Society of Nephrology, Vol. 4, No. 6, 2009, pp. 1051-1056 doi:10.2215/CJN.05931108

[27] H. P. Peters, C. M. Laarakkers, D. W. Swinkels, et al., "Serum Hepcidin-25 Levels in Patients with Chronic Kidney Disease Are Independent of Glomerular Filtration Rate," Nephrology Dialysis Transplantation, Vol. 25, No. 3, 2010, pp. 848-853. doi:10.1093/ndt/gfp546

[28] G. Weiss, I. Theurl, S. Eder, et al., "Serum Hepcidin Concentration in Chronic Haemodialysis Patients: Associations and Effects of Dialysis, Iron and Erythropoietin Therapy," European Journal of Clinical Investigation, Vol. 39, No. 10, 2009, pp. 883-890. doi:10.1111/j.1365-2362.2009.02182.x

[29] B. Ford, C. Eby, M. Scott, et al., "Intra-Individual Variability in Serum Hepcidin Precludes Its Use as a Marker of Iron Status in Hemodialysis Patients," Kidney International, Vol. 78, 2010, pp. 769-773. doi:10.1038/ki.2010.254

[30] S. Stancu, L. Barsan, A. Stanciu, et al., "Can the Response to Iron Therapy Be Predicted in Anemic Nondialysis Patients with Chronic Kidney Disease?" Clinical Journal of the American Society of Nephrology, Vol. 5, No. 3, 2010, pp. 409-416. doi:10.2215/CJN.04280609

[31] B. J. Sasu, K. S. Cooke, T. L. Arvedson, et al., "Antihepcidin Antibody Treatment Modulates Iron Metabolism and Is Effective in a Mouse Model of Inflammation-Induced Anemia," Blood, Vol. 115, No. 17, 2010, pp. 36163624. doi:10.1182/blood-2009-09-245977

[32] R. Fudin, J. Jaichenko, A. Shostak, M. Bennett and L. Gotloib, "Nephron Correction of Uremic Iron Deficiency Anemia in Hemodialyzed Patients: A Prospective Study," Vol. 79, No. 3, 1998, pp. 299-305. doi:10.1159/000045053

[33] I. C. MacDougall, B. Tucker, J. Thompson, C. R. Tomson, L. R. Baker and A. E. Raine, "A Randomized Controlled Study of Iron Supplementation in Patients Treated with EPO," Kidney International, Vol. 50, No. 5, 1996, pp. 1694-1699. doi:10.1038/ki.1996.487

[34] R. L. Wingard, R. A. Parker, N. Ismail and R. M. Hakim, "Efficacy of Oral Iron Therapy in Patients Receiving Recombinant Human EPO," American Journal of Kidney Diseases, Vol. 25, No. 3, 1995, pp. 433-439. doi:10.1016/0272-6386(95)90105-1

[35] R. Provenzano, B. Schiller, M. Rao, D. Coyne, L. Brenner and B. J. Pereira, "Ferumoxytol as an Intravenous Iron Replacement Therapy iN Hemodialysis Patients," Clinical Journal of the American Society of Nephrology, Vol. 4, No. 2, 2009, pp. 386-393. doi:10.2215/CJN.02840608

[36] "K/DOQI Clinical Practice Guidelines and Clinical Practice Recommendations for Anemia in Chronic Kidney Disease," American Journal of Kidney Diseases, Vol. 47, Suppl. 3, 2006, pp. S1-S3. doi:10.1053/S0272-6386(05)01814-7

[37] J. Stoves, H. Inglis and C. G. Newstead, “A Randomized Study of Oral vs. Intravenous Iron Supplementation in Patients with Progressive Renal Insufficiency Treated with EPO," Nephrology Dialysis Transplantation, Vol. 16, No.

\section{5, 2001, pp. 967-974. doi:10.1093/ndt/16.5.967}

[38] C. Charytan, W. Ounibi and G. R. Bailie, "Comparison of Intravenous Iron Sucrose to Oral Iron in the Treatment of Anemic Patients with Chronic Kidney Disease Not on Dialysis," Nephron Clinical Practice, Vol. 100, No. 3, 2005, pp. c55-c62.

[39] D. B. Van Wyck; M. Roppolo, C. O. Martinez, R. M. Mazey and S. McMurray, "A Randomized, Controlled Trial Comparing IV Iron Sucrose to Oral Iron in Anemic Patients with Non Dialysis-Dependent CKD," Kidney International, Vol. 68, No. 6, 2005, pp. 2846-2856 doi:10.1111/j.1523-1755.2005.00758.x

[40] R. Agarwal, A. R. Rizkala, B. Bastani, M. O. Kaskas, D. J. Leehey and A. Besarab, "A Randomized Controlled Trial of Oral versus Intravenous Iron in Chronic Kidney Disease," American Journal of Nephrology, Vol. 26, No. 5, 2006, pp. 445-454. doi:10.1159/000096174

[41] B. S. Spinowitz, A. T. Kausz, J. Baptista, S. D. Noble, R. Sothinathan, M. V. Bernardo, L. Brenner and B. J. Pereira, "Ferumoxytol for Treating Iron Deficiency Anemia in CKD," Journal of the American Society of Nephrology, Vol. 19, No. 8, 2008, pp. 1599-1605 doi:10.1681/ASN.2007101156

[42] K. R. Bridges and K. E. Hoffman, "The Effects of Ascorbic Acid on the Intracellular Metabolism of Iron and Ferritin," Journal of Biological Chemistry, Vol. 261, No. 30, 1986, pp. 14273-14277.

[43] D. A. Lipschitz, T. H. Bothwell, H. C. Seftel, et al., "The Role of Ascorbic Acid in the Metabolism of Storage Iron," British Journal of Haematology, Vol. 20, No. 2, 1971, pp. 155-163. doi:10.1111/j.1365-2141.1971.tb07024.x

[44] A. Goldberg, "The Enzymic Formation of Haem by the Incorporation of Iron into Protoporphyrin; Importance of Ascorbic Acid, Ergothioneine and Glutathione," British Journal of Haematology, Vol. 5, No. 2, 1959, pp. 150157. doi:10.1111/j.1365-2141.1959.tb04020.x

[45] R. Deicher, F. Ziai, A. Habicht, et al., "Vitamin C Plasma Level and Response to Erythropoietin in Patients on Maintenance Haemodialysis," Nephrology Dialysis Transplantation, 2004, Vol. 19, 2319. doi:10.1093/ndt/gfh260

[46] K. Gastaldello, A. Vereerstraeten, T. Nzame-Nze, J. L. Vanherweghem and C. Tielemans, "Resistance to EPO in Iron-Overloaded Hemodialysis Patients Can Be Overcome by Ascorbic Acid Administration," Nephrology Dialysis Transplantation, Vol. 10, Suppl. 6, 1995, pp. 44-47.

[47] D. C. Tarng, Y. H. Wei, T. P. Huang, et al., "Intravenous Ascorbic Acid as an Adjuvant Therapy for Recombinant Erythropoietin in Hemodialysis Patients with Hyperferritinemia," Kidney International, Vol. 55, No. 6, 1999, pp. 2477-2486. doi:10.1046/j.1523-1755.1999.00479.x

[48] W. D. Sirover, A. A. Siddiqui and R. L. Benz, "Beneficial Hematologic Effects of Daily Oral Ascorbic Acid Therapy in ESRD Patients with Anemia and Abnormal Iron Homeostasis: A Preliminary Study," Renal Failure, Vol. 30, No. 9, 2008, pp. 884-889. doi: $10.1080 / 08860220802353884$

[49] K. Keven, S. Kutlay, G. Nergizoglu and S. Ertürk, "Randomized, Crossover Study of the Effect of Vitamin C on EPO Response in Hemodialysis Patients," American Jour- 
nal of Kidney Diseases, 2003, Vol. 41, No. 6, pp. 12331239. doi:10.1016/S0272-6386(03)00356-1

[50] Y. Taji, T. Morimoto, K. Okada, et al., "Effects of Intravenous Ascorbic Acid on Erythropoiesis and Quality of Life in Unselected Hemodialysis Patients," Journal of Nephrology, Vol. 17, No. 4, 2004, pp. 537-543.

[51] J. Deira, J. Diego, R. Martínez, et al., "Comparative Study of Intravenous Ascorbic Acid versus Low-Dose Desferroxamine in Patients on Hemodialysis with Hyperferritinemia," Journal of Nephrology, Vol. 16, No. 5, 2003, pp. 703-709.

[52] V. Giancaspro, M. Nuzziello, G. Pallotta, et al., "Intravenous Ascorbic Acid in Hemodialysis Patients with Functional Iron Deficiency: A Clinical Trial," Journal of $\mathrm{Ne}$ phrology, Vol. 13, No. 6, 2000, pp. 444-449.

[53] N. Attallah, Y. Osman-Malik, S. Frinak and A. Besarab, "Effect of Intravenous Ascorbic Acid in Hemodialysis Patients with EPO-Hyporesponsive Anemia and Hyperferritinemia," American Journal of Kidney Diseases, Vol. 47, No. 4, 2006 pp. 644-654. doi:10.1053/i.ajkd.2005.12.025

[54] V. Deved, P. Poyah, M. T. James, et al., "Ascorbic Acid for Anemia Management in Hemodialysis Patients: A Systematic Review and Meta-Analysis," American Journal of Kidney Diseases, Vol. 54, No. 6, 2009, pp. 10891097. doi:10.1053/j.ajkd.2009.06.040

[55] P. Balcke, P. Schmidt, J. Zazgornik, et al., "Ascorbic Acid Aggravates Secondary Hyperoxalemia in Patients on Chronic Hemodialysis," Annals of Internal Medicine, Vol. 101, No. 3, 1984, pp. 343-344.

[56] C. Pru, J. Eaton and C. Kjellstrand, "Vitamin C Intoxication and Hyperoxalemia in Chronic Hemodialysis Patients," Nephron, Vol. 39, No. 2, 1985, pp. 112-116. doi:10.1159/000183353

[57] J. Eiselt, J. Racek, L. Trefil and K. Opatrný Jr., "Effects of a Vitamin E-Modified Dialysis Membrane and Vitamin C Infusion on Oxidative Stress in Hemodialysis Patients," Artificial Organs, 2001, Vol. 25, No. 6, pp. 430436. doi:10.1046/j.1525-1594.2001.025006430.x

[58] C. Canavese, M. Petrarulo, P. Massarenti, et al., "LongTerm, Low-Dose, Intravenous Vitamin C Leads to Plasma Calcium Oxalate Supersaturation in Hemodialysis Patients," American Journal of Kidney Diseases, Vol. 45, No. 3, 2005, pp. 540-549. doi:10.1053/j.ajkd.2004.10.025

[59] "SECTION III. Treatment of Renal Anaemia," Nephrology Dialysis Transplantation, Vol. 19, Suppl. 2, 2004, pp. ii16-ii31. doi:10.1093/ndt/gfh1026

[60] C. J. Rebouche and H. Seim, "Carnitine Metabolism and Its Regulation in Microorganisms and Mammals," Annual Review of Nutrition, Vol. 18, No. 1, 1998, pp. 39-61. doi:10.1146/annurev.nutr.18.1.39

[61] T. A. Golper, S. Goral, B. N. Becker and C. B. Langman, "L-Carnitine Treatment of Anemia," American Journal of Kidney Diseases, Vol. 41, Suppl. 42, 2003, pp. S27-S34. doi:10.1016/S0272-6386(03)00114-8

[62] Y. Kitamura, K. Satoh, T. Satoh, et al., "Effect of LCarnitine on Erythroid Colony Formation in Mouse Bone Marrow Cells," Nephrology Dialysis Transplantation, Vol.
20, No. 5, 2005, pp. 981-984. doi:10.1093/ndt/gfh758

[63] J. M. Hurot, M. Cucherat, M. Haugh and D. Fouque, "Effects of L-Carnitine Supplementation in Maintenance Hemodialysis Patients: A Systematic Review," Journal of the American Society of Nephrology, Vol. 13, No. 2002, pp. 708-714.

[64] W. D. Labonia, "L-Carnitine Effects on Anemia in Hemodialyzed Patients Treated with Erythropoietin," American Journal of Kidney Diseases, 1995, Vol. 26, pp. 757764. doi:10.1016/0272-6386(95)90439-5

[65] A. A. Sabry, "The Role of Oral L-Carnitine Therapy in Chronic Hemodialysis Patients," Saudi Journal of Kidney Diseases and Transplantation, Vol. 21, No. 3, 2010, pp. 454-459.

[66] U. Caruso, L. Leone, E. Cravotto and D. Nava, "Effects of L-Carnitine on Anemia in Aged Hemodialysis Patients Treated with Recombinant Human Erythropoietin: A Pilot Study," Dialysis \& Transplantation, Vol. 27, 1998, pp. 498-506.

[67] J. Kletzmayr, G. Mayer, E. Legenstein, et al., "Anemia and Carnitine Supplementation in Hemodialyzed Patients," Kidney International Supplements, Vol. 55, Suppl. 69, 1999, pp. S93-S96. doi:10.1046/j.1523-1755.1999.055Suppl.69093.x

[68] E. C. Vaux, D. J. Taylor, P. Altmann, et al., "Effects of Carnitine Supplementation on Muscle Metabolism by the Use of Magnetic Resonance Spectroscopy and near-Infrared Spectroscopy in End-Stage Renal Disease," Nephron Clinical Practice, Vol. 97, No. 2, 2004, pp. c41-c48. doi:10.1159/000078399

[69] J. Semeniuk, K. F. Shalansky, N. Taylor, et al., "Evaluation of the Effect of Intravenous L-Carnitine on Quality of Life in Chronic Hemodialysis Patients," Clinical Nephrology, Vol. 54, No. 6, 2000, pp. 470-477.

[70] A. Evans, "Dialysis-Related Carnitine Disorder and Levocarnitine Pharmacology," American Journal of Kidney Diseases, Vol. 41, Suppl. 4, 2003, pp. S13-S26. doi:10.1016/S0272-6386(03)00113-6

[71] M. A. Bain, R. Faull, R. W. Milne and A. M. Evans, "Oral L-Carnitine: Metabolite Formation and Hemodialysis," Current Drug Metabolism, Vol. 7, No. 7, 2006, pp. 811816. doi:10.2174/138920006778520561

[72] G. Eknoyan, D. L. Latos and J. Lindberg, "National Kidney Foundation Carnitine Consensus Conference. Practice Recommendations for the Use of L-Carnitine in Dialysis-Related Carnitine Disorder. National Kidney Foundation Carnitine Consensus Conference," American Journal of Kidney Diseases, Vol. 41, No. 4, 2003, pp. 868-876. doi:10.1016/S0272-6386(03)00110-0

[73] J. Bienvenu, C. Doche, M. C. Gutowski, et al. "Production of Proinflammatory Cytokines and Cytokines Involved in the TH1/TH2 Balance is Modulated by Pentoxifylline," Journal of Cardiovascular Pharmacology, Vol. 25, Suppl. 2, 1995, pp. S80-S84. doi:10.1097/00005344-199500252-00017

[74] N. Benbernou, S. Esnault, G. Potron and M. Guenounou, "Regulatory Effects of Pentoxifylline on T-Helper CellDerived Cytokine Production in Human Blood Cells," 
Journal of Cardiovascular Pharmacology, Vol. 25, Suppl. 2, 1995, pp. S75-S79. doi:10.1097/00005344-199500252-00016

[75] J. F. Navarro, C. Mora, J. García, et al., "Effects of Pentoxifylline on the Haematologic Status in Anaemic Patients with Advanced Renal Failure," Scandinavian Journal of Urology and Nephrology, Vol. 33, 1999, pp. 121125. doi:10.1080/003655999750016113

[76] A. Cooper, A. Mikhail, M. W. Lethbridge, et al., "Pentoxifylline Improves Hemoglobin Levels in Patients with Erythropoietin-Resistant Anemia in Renal Failure," Journal of the American Society of Nephrology, Vol. 15, No. 7, 2004, pp. 1877-1882.

doi:10.1097/01.ASN.0000131523.17045.56

[77] G. Sirken, S. C. Kung and R. Raja, "Decreased Erythropoietin Requirements in Maintenance Hemodialysis Patients with Statin Therapy," Asaio Journal, Vol. 49, 2003, pp. 422-425.

[78] K. Tangdhanakanond and R. Raja, "Effect of Statins on EPO Responsiveness in Type 2-Diabetic versus Non-Diabetic Hemodialysis Patients," Clinical Nephrology, Vol. 73, No. 1, 2010, pp. 1-6.

[79] C. K. Chiang, S. Y. Yang, Y. S. Peng, S. P. Hsu, M. F. Pai, J. W. Huang, K. Y. Hung and K. D. Wu, "Atorvastatin Increases EPO-Stimulating Agent Hypo Responsiveness in Maintenance Hemodialysis Patients: Role of Anti-Inflammation Effects," American Journal of Nephrology, Vol. 29, No. 5, 2009, pp. 392-397. doi: $10.1159 / 000169658$

[80] United States Renal Data System, "USRDS 2010 Annual Data Report: Atlas of Chronic Kidney Disease and EndStage Renal Disease in the United States, National Institutes of Health," National Institute of Diabetes and Digestive and Kidney Diseases, Bethesda, 2010.

[81] J. L. Teruel, R. Marcen, J. Navarro-Antolin, A. Aguilera, G. Fernandez-Juarez and J. Ortuo, "Androgen versus EPO for the Treatment of Anemia in Hemodialyzed Patients: A Prospective Study," Journal of the American Society of Nephrology, 1996, Vol. 7, No. 1, pp. 140-144.

[82] A. Gascn, J. J. Belvis, F. Berisa, E. Iglesias, V. Estopin and J. L. Teruel, "Nandrolone Decanoate Is a Good Alternative for the Treatment of Anemia in Elderly Male Patients on Hemodialysis," Geriatric Nephrology and Urology, Vol. 9, No. 2, 1999, pp. 67-72. doi:10.1023/A:1008306301255

[83] J. F. Navarro, C. Mora-Fernandez, A. Rivero, M. Macia, E. Gallego, J. Chahin, M. L. Mendez and J. Garcia, "Androgens for the Treatment of Anemia in Peritoneal Dialysis Patients," Advances in Peritoneal Dialysis, Vol. 14, 1998, pp. 232-235.

[84] J. F. Navarro, C. Mora, M. Macia and J. Garcia, "Randomized Prospective Comparison between EPO and Androgens in CAPD Patients," Kidney International, Vol. 61, No. 4, 2002, pp. 1537-1544. doi:10.1046/j.1523-1755.2002.00271.x

[85] S. H. Ballal, D. T. Domoto, D. C. Polack, P. Marciulonis and K. J. Martin, "Androgens Potentiate the Effects of EPO in the Treatment of Anemia of End-Stage Renal Disease," American Journal of Kidney Diseases, Vol. 17, No. 1, 1991, pp. 29-33.

[86] J. S. Bern, M. R. Rudnick and R. M. Cohen, “A Controlled Trial of Recombinant Human Erythropoietin and Nandrolone Decanoate in the Treatment of Anemia in Patients on Hcronic Hemodialysis," Clinical Nephrology, Vol. 37, No. 5, 1992, pp. 264-267.

[87] W. J. Gaughan, K. A. Liss, S. R. Dunn, et al., "A 6-Month Study of Low-Dose Recombinant Human Erythropoietin Alone and in Combination with Androgens for the Treatment of Anemia in Chronic Hemodialysis Patients," American Journal of Kidney Diseases, Vol. 30, No. 4, 1997, pp. 495-500. doi:10.1016/S0272-6386(97)90307-3

[88] H. Sheashaa, W. Abdel-Razek, A. El-Husseini, et al., "Use of Nandrolone Decanoate as an Adjuvant for Erythropoietin Dose Reduction in Treating Anemia in Patients on Hemodialysis," Nephron Clinical Practice, Vol. 99, No. 4, 2005, pp. c102-c106.

[89] A. V. Kshirsagar, C. Poole, A. Mottl, D. Shoham, N. Franceschini, G. Tudor, M. Agrawal, C. Denu-Ciocca, E. Magnus Ohman and W. F. Finn, "N-Acetylcysteine for the Prevention of Radiocontrast Induced Nephropathy: A MetaAnalysis of Prospective Controlled Trials," Journal of the American Society of Nephrology, Vol. 15, No. 3, 2004, pp. 761-769. doi:10.1097/01.ASN.0000116241.47678.49

[90] M. J. Smilkstein, G. L. Knapp, K. W. Kulig, B. H. Rumack, "Efficacy of Oral N-Acetylcysteine in the Treatment of Acetaminophen Overdose. Analysis of the National Multicenter Study (1976 to 1985)," New England Journal of Medicine, Vol. 319, No. 24, 1988, pp. 1557-1562. doi:10.1056/NEJM198812153192401

[91] ACT Investigators, "Acetylcysteine for Prevention of Renal Outcomes in Patients Undergoing Coronary and Peripheral Vascular Angiography: Main Results from the Randomized Acetylcysteine for Contrast-Induced Nephropathy Trial (ACT)," Circulation, Vol. 124, No. 11, 2011, pp. 1250-1259.

[92] "KDIGO Clinical Practice Guideline for Acute Kidney Injury," Kidney International Supplements, Vol. 2, No. 1, 2012, pp. 8-12. doi:10.1038/kisup.2012.7

[93] S.-P. Hsu, C.-K. Chiang, S.-Y. Yang and C.-T. Chien, "N-Acetylcysteine for the Management of Anemia and Oxidative Stress in Hemodialysis Patients," Nephron Clinical Practice, Vol. 116, No. 3, 2010, pp. c207-c216.

[94] G. Swarnalatha, R. Ram, P. Neela, M. U. Naidu, K. V. Dakshina Murty, "Oxidative Stress in Hemodialysis Patients Receiving Intravenous Iron Therapy and the Role of N-Acetylcysteine in Preventing Oxidative Stress," Saudi Journal of Kidney Diseases and Transplantation, 2010, Vol. 21, No. 5, pp. 852-888.

[95] N. A. Finnigan, M. M. Chernick and R. L. Benz, "Nephrology, N-Acetylcysteine (NAC) May Improve Erythropoietin Resistant Anemia (ERA) in Hemodialysis Patients [SAPO2587] ASN Renal Week 2010 Abstracts." 